\section{CHEMICAL COMPOSITION OF SPUTTERED COCR FOR PERPENDICULAR RECORDING}

T. Masuda, W. J.M. A. Geerts, L. J. Hanekamp and J.C. Lodder

University of Twente

P. O. Box 217, 7500AE Enschede, The Netherlands

INTRODUCTION: For high density perpendicular recording media, sputtered CoC films are considered one of the most expected materials for applications. To understand this complex system recently a lot of effort has been put into the study of the surface magnetic behaviour. A lack of sufficient data about the chemical state of the surface makes it very difficult to interpret the results obtained by these experiments. In this paper we publish the results obtained by performing AES on CoCr samples with different thicknesses and to correlate magnetic and chemical data. Also XPS measurements were performed.

EXPERIMENTS: All the samples were prepared by RF-sputtering. Six kinds of $\mathrm{CoCr}$ films were prepared under the condition of the previous report [1]. XRFS was adopted to determine the average film composition and thickness. The film thicknesses at AES measurements were normalized by comparison with XRFS results. The AES sputtering rate was determined from this result. The AES analyses were performed in a PHI-600. Standard measurement condition were: primary beam energy: $3 \mathrm{keV}$, beam current: 100nA, excitation beam area: approximately $0.2 \mu \mathrm{m}$, measuring area: approximately $10 \mu \mathrm{m}$ (scanning mode). In order to clean the films and appreciate depth profiling, Ar ion bombardment was carrled out. A 3.skeV lon beam was adopted for the sputtering with an emission current of $2.5 \mathrm{~mA}$ for an area of $2 \times 2 \mathrm{~mm}$. To determine the magnetic state of the films we measured the perpendicular hysteresis curve by VSM and M.O. Kerr tracer [1].

RESULTS: Fig. 1 shows the average Auger peak to peak intensity of $\mathrm{Co}, \mathrm{Cr}$ and 0 from a series of six $\mathrm{CoCr}$ films with different thicknesses along the depth direction from the surface. When we consider the surface region, there are many considerable factors, for example physical adsorption layers ( $\mathrm{CO}, \mathrm{CmHnO}_{\mathrm{H}}$ etc.), chemisorption layers (soon change into oxide or hydroxide) and oxidized Co and Cr. From this figure, the thickness of the adsorption layer are consldered not to depend on the sample thicknesses. Most of the surface or every sample is considered to be physically adsorbed, therefore the first sputtered layer is regarded as an adsorbed layer (left or the dashed line). Aystem the electron bolbardment and/or the Ar collision in a vacuum system $\dot{8}$ By the electron bombar $2 \times 10^{-} 9_{\text {Tor }}$ ) the from the surfaces of the films. Then we considered that these adsorbed initial surfaces of the fllms. intial lavers artered aton which are taken to be mainl $\mathrm{C}_{\mathrm{H}} \mathrm{H}$ and $\mathrm{O}$. Co peak increases motonously and around a depth of $50 \mathrm{~A}$ it reaches to a constant value. Meanuhile the $C r$ peak has its threshold around a depth of A. In Fig. 2 the $\mathrm{Cr}(489 \mathrm{eV}) / \mathrm{Co}(775 \mathrm{ev})$ peak ratio is given as a function of the depth from the surface. The same tendency is found for all the six samples. The Co/Cr peak ratio shows the $\mathrm{Cr}$ concentration near the surface- 1
$\mathrm{Cr}$ is more concentrated than $\mathrm{Co}$ in the top layer. The segregated $\mathrm{Cr}$ state is being studied. This is also suggested in ref. [2] with the as-grown surface of the bulk casting $\mathrm{CoC}_{\Gamma}$ samples by the results of XPS. Fig. 3 shows the Auger peak intensity of 0 at the top layer for six different samples. The 0 takes a critical value of around $100 \mathrm{~nm}$ thickness. These results coincide with those of the VSM coercivity (from the total value of the $f(1 \mathrm{~m})$ and the surface coercivity (M.O. Kerr) [1]. Further results will be discussed with the analyses of XPS in relation to the magnetic properties at the surface.

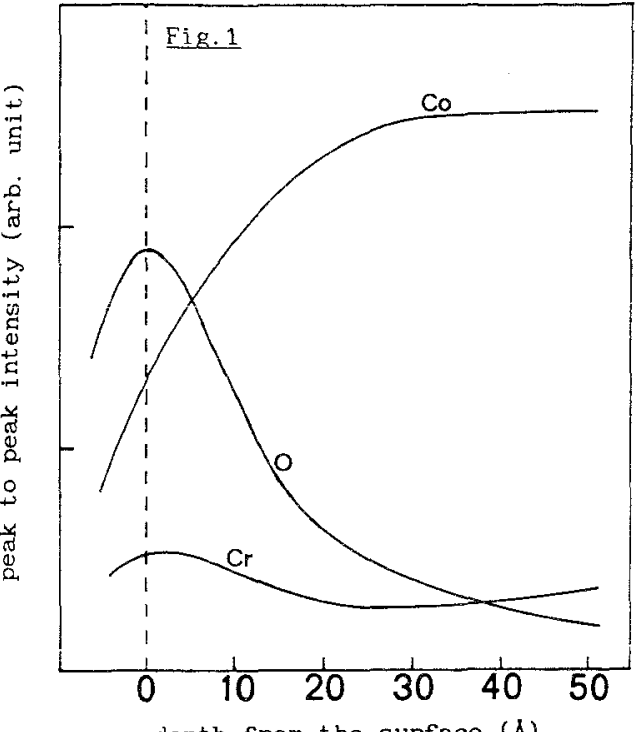

depth from the surface (A)

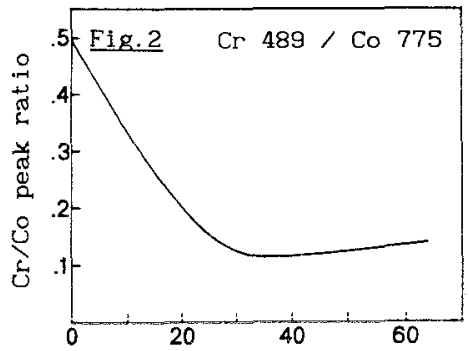

depth from the surface $(A)$

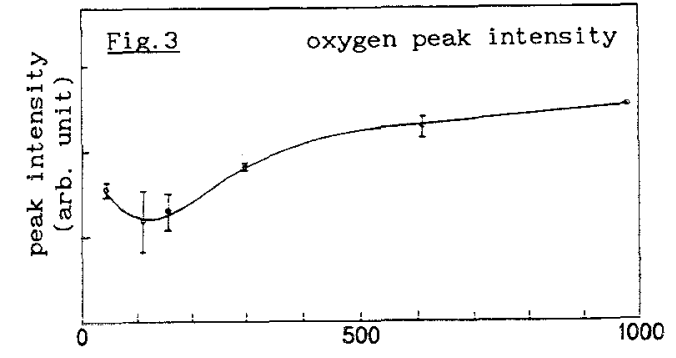

film thickness $(\mathrm{nm})$

REFERENCES:

1] W. J.M.A.Geerts, J.G. Th. te Lintelo, J.C.Lodder and Th. J.A. Popma, IEEE Trans. Magn. in press (1989)

[2] D. E. Fowler and J. Rogozik, J. Vac. Sci. Technol. A6(3), 928 (1988). 